\section{Combining two-stage surgery and denosumab treatment in a patient with giant cell tumour of the lumbar spine with intraperitoneal growth}

\section{INTRODUCTION}

Giant cell tumour (GCT) is a well-known primary bone tumour, and its incidence in the mobile spine (above the sacrum) ranges from $1.4 \%$ to $9.4 \% .{ }^{1}$ There are only very few studies that focused on GCT of the mobile spine with intraperitoneal growth, especially of the lumbar spine; thus, there is still shortage of imaging proof. ${ }^{2}$ GCTs of the bone are Receptor Activator for Nuclear Factor- $\kappa$ (RANK)/RANK-ligand (RANKL) positive, aggressive and progressive osteolytic tumours. Denosumab, a RANKL inhibitor, has been approved by the US Food and Drug Administration for adults and skeletally mature adolescents with unresectable GCT or when surgical resection is likely to result in severe complications since $2013 .{ }^{4}$ Herein, we are presenting a brief analysis of a case of GCT in the lumbar spine with intraperitoneal growth treated with two-stage surgery that combined posterior and anterior approaches, and denosumab treatment postoperatively. Our focus is to emphasise the importance of considering GCT as a diagnosis and guiding the proper perioperative management on surgical treatment.

\section{CASE DESCRIPTION}

A 24-year-old previously healthy woman presented to our institution with a 4-month history of continuous progressive back pain and acute radiculopathy of the left lower limb in November 2014. Plain radiograph showed pathological fracture of L4 and compensatory trunk deviation (figure 1A). CT and MRI of the spine revealed significant bone destruction and pathological fracture of L4, secondary spinal canal stenosis, and shadow of a soft tissue mass around L4 with intraperitoneal growth (figure 1B-D). She denied history of injury and any underlying diseases. The general physical examination was remarkable for pressure pain and percussion pain in the lumbar spinal region, and limited range of motion and pain in all planes of movement. Routine laboratory studies were almost within normal range. The three-dimensional reconstruction CT also showed significant bone destruction and pathological fracture of L4 (figure 1E). Imaging data indicated the skeletal abnormality of L4 was with high suspicion of a GCT. Considering the large volume of the mass and its intraperitoneal invasion, a two-stage procedure that combined posterior and anterior approaches was designed. Posterior spinal canal decompression, internal fixation and reconstruction with bone cement were performed in November, followed by anterior tumour resection, internal fixation and reconstruction with cement in December (figure $1 \mathrm{~F}$ ). The postoperative pathology confirmed a GCT (figure 1G). Consequently, a GCT in L4, grade 1, was diagnosed. Postoperatively, the patient underwent rehabilitation therapy and was monitored as an outpatient. She then received the treatment with denosumab (120 mg; Amgen, Thousand Oaks, California, USA), that is, subcutaneous injections of $120 \mathrm{mg}$ denosumab monthly with loading doses on days 8 and 15 of cycle 1 for a total of 12 months. Daily supplements of vitamin D and a calcium supplement were prescribed orally to avoid hypocalcaemia. No major complications were associated with surgical treatment and

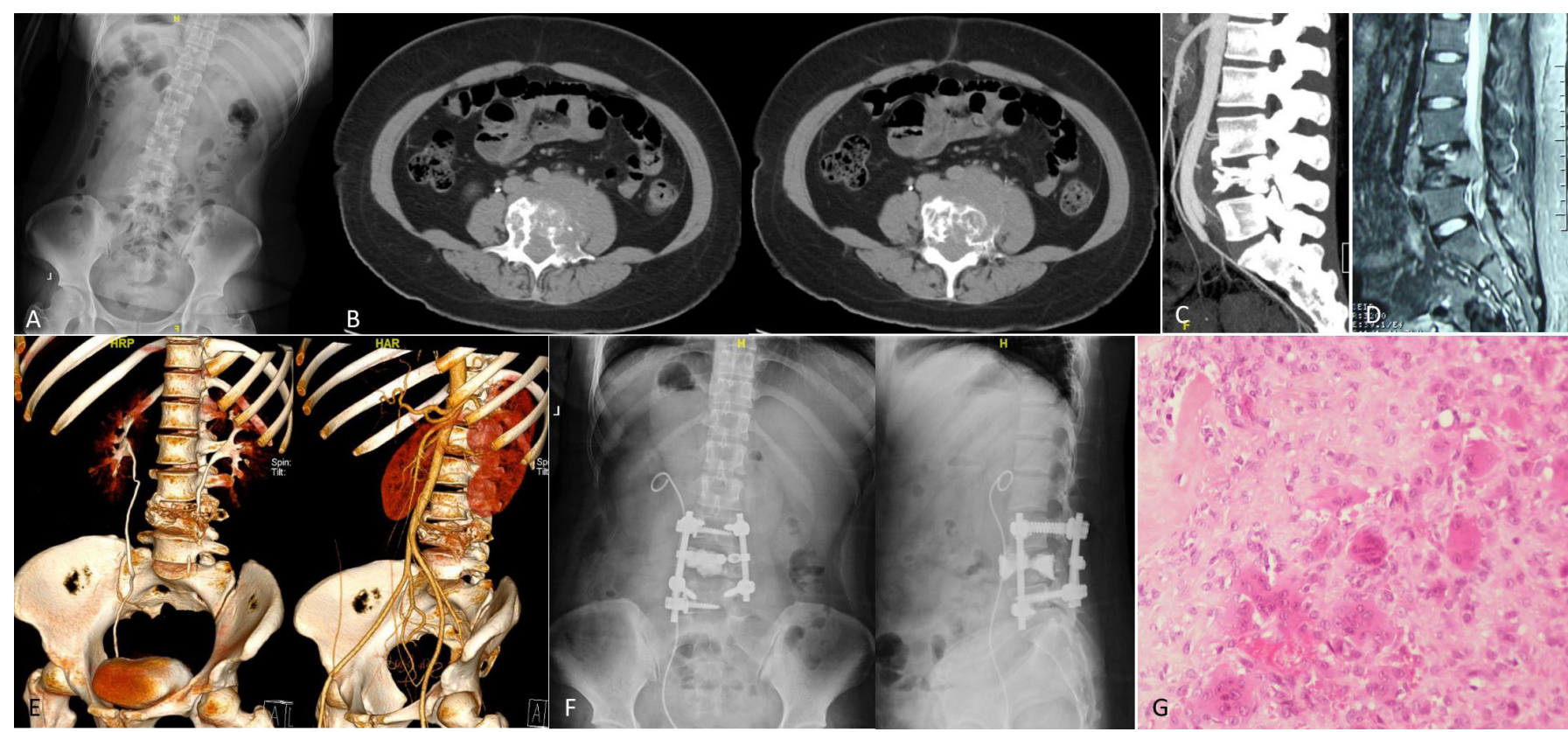

Figure 1 A rare case of a giant cell tumour in the lumbar spine with intraperitoneal growth treated with two-stage surgery and denosumab in a 24-year-old woman. (A) Posteroanterior X-ray film of the lumbar spine revealed pathological fracture of L4 and compensatory trunk deviation. (B-D) Preoperative CT scan and MRI revealed significant bone destruction and pathological fracture of $L 4$, secondary spinal canal stenosis, and shadow of a soft tissue mass around L4 with intraperitoneal growth. (E) Three-dimensional reconstruction CT showed significant bone destruction and pathological fracture of L4. (F) Posteroanterior and lateral X-ray films of the spine revealed instrumentation and cement augmentation were satisfactory. (G) Histopathology confirmed a giant cell tumour of grade 1 in L4 (HE staining, original magnification $\times 200$ ). 
denosumab administration. Good responses were seen at subsequent follow-up based on the patient's report of symptoms, physical examination and radiological imaging assessments. At a 3-year follow-up visit, the patient was doing well with no evidence of local progress or new symptoms.

\section{CONCLUSION}

In conclusion, we present an extremely rare case of GCT of the lumbar spine with intraperitoneal invasion that was successfully excised by a two-stage procedure that combined posterior and anterior approaches, followed by denosumab treatment, which has not been previously well reported. Combination of surgical treatment and denosumab treatment can be a definite therapy of choice in treating large GCTs at challenging anatomical locations, such as the spinal regions. Our case highlights the significance of early diagnosis and proper treatment of GCT of the mobile spine with intraperitoneal invasion.

\section{Shuzhong Liu, ${ }^{1}$ Xi Zhou, ${ }^{1}$ An Song, ${ }^{2}$ Zhen Huo, ${ }^{3}$ Yipeng Wang, ${ }^{1}$ Yong Liu ${ }^{1}$ \\ ${ }^{1}$ Department of Orthopaedic Surgery, Peking Union Medical College Hospital, Chinese Academy of Medical Science \& Peking Union Medical College, Beijing, China ${ }^{2}$ Department of Endocrinology, Key Laboratory of Endocrinology, National Health and Family Planning Commission, Peking Union Medical College Hospital, Chinese Academy of Medical Science \& Peking Union Medical College, Beijing, China ${ }^{3}$ Department of Pathology, Peking Union Medical College Hospital, Chinese Academy of Medical Science \& Peking Union Medical College, Beijing, China}

Correspondence to Professor Yong Liu, Department of Orthopaedic Surgery, Peking Union Medical College Hospital, Peking Union Medical College and Chinese Academy of Medical Sciences, Beijing 100730, China; liuyong_pumch@163.com

Contributors All the listed authors contributed significantly to manuscript preparation. SL wrote the first draft of the manuscript and submitted the manuscript. $\mathrm{XZ}, \mathrm{ZH}$ and AS were in charge of the patient and collected the data. SL and YL did the follow-up of the patient, and YW and YL critically revised the manuscript. SL, XZ and AS contributed equally to this paper. All authors approved the final version.

Funding The authors have not declared a specific grant for this research from any funding agency in the public, commercial or not-for-profit sectors.
Competing interests None declared.

\section{Patient consent Obtained.}

Provenance and peer review Not commissioned; externally peer reviewed.

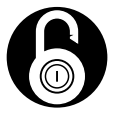

\section{OPEN ACCESS}

Open access This is an open access article distributed in accordance with the Creative Commons Attribution Non Commercial (CC BY-NC 4.0) license, which permits others to distribute, remix, adapt, build upon this work non-commercially, and license their derivative works on different terms, provided the original work is properly cited, appropriate credit is given, any changes made indicated, and the use is non-commercial. See: http://creativecommons.org/licenses/by-nc/4.0/

(C) Author(s) (or their employer(s)) 2019. Re-use permitted under CC BY-NC. No commercial re-use. See rights and permissions. Published by BMJ.

\section{Check for updates}

To cite Liu S, Zhou X, Song A, et al. Postgrad Med J 2019;95:106-107.

Received 3 July 2018

Revised 13 October 2018

Accepted 27 October 2018

Published Online First 13 November 2018

Postgrad Med J 2019;95:106-107.

doi:10.1136/postgradmedj-2018-135972

\section{REFERENCES}

1 Boriani S, Bandiera S, Casadei R, et al. Giant cell tumor of the mobile spine: a review of 49 cases. Spine 2012;37:E37-45.

2 Munoz-Bendix C, Cornelius JF, Bostelmann R, et al. Giant cell tumor of the lumbar spine with intraperitoneal growth: case report and review of literature. Acta Neurochir 2013;155:1223-8

3 Hu Y, Xia Q, Ji J, et al. One-stage combined posterior and anterior approaches for excising thoracolumbar and lumbar tumors: surgical and oncological outcomes. Spine 2010:35:590-5.

4 Law GW, Yeo NEM, Howe TS, et al. Recommencement of denosumab for unresectable giant cell tumor of the cervical spine: a case report. Spine 2018;43:E551-6. 